\title{
What does a team expect from its doctor?
}

\author{
R.D.A. Dodds, O.B.E., M.A., F.R.C.S. \\ Captain, Great Britain Hockey Team, Gold Medallists, Seoul Olympics, 1988
}

It is the wish of every athlete to be in perfect health at all times. If he becomes ill or injured, he wants to be back in full training or competition by yesterday clearly not an ideal patient especially if rest is needed. In a team sport the doctor has sixteen or so such patients and has to care for them individually as well as considering the well-being of the team as a whole. On top of this there's the acute low back pain and sciatica of one official after 'warming up' the goalkeepers, or the anterior talo-fibular ligament sprain of another sustained in a fall off the sixteenth tee in a pretournament relaxing golf afternoon, not to mention the unstable angina of a fellow airline passenger! These have all occurred on recent hockey trips and thus the doctor's role is truly wide-ranging. So what does an international team actually want from its doctor? The players are all above-average sportsmen and therefore expect and deserve comparable medical care.

Each player will have his own general practitioner. Many G.P.s do not and indeed could not be expected to understand the needs of an elite sportsman, and it is therefore essential that such players have access to more specialized medical care. The team doctor should be able either to supply this care or to coordinate it. In hockey the governing body provides private health care insurance for all national squad members which, regrettably, is necessary to facilitate this. I believe the National Health Service is simply not able to cope with situations that, were they not involving an athlete in sight of a major championship or the Olympics, would be classified as non-urgent. The player wants a doctor who is approachable, easily contactable and with good contacts.

I have found that most up and coming, and even some established hockey players do not understand the physiology and principles behind training and preparing for competition physically or mentally. Prevention of illness or injury is better than cure and players want advice on training, taking adequate rest and diet. This may in part be the coach's role but the doctor must be able to supply such advice. A problem arises when a player is injured during the selection/ preparation period before a tournament. Every squad member is keen to play, both to try and impress the selectors and to prevent anyone else from doing so! For this latter reason players are tempted to play carrying injuries, with the risk of aggravating things. These players need medical and psychological support from

R.D.A. Dodds, Surgical Registrar, St Richard's Hospital, Chichester, Sussex, UK

(C) 1989 Butterworth \& Co (Publishers) Ltd 0306-3674/89/030145-02 \$03.00

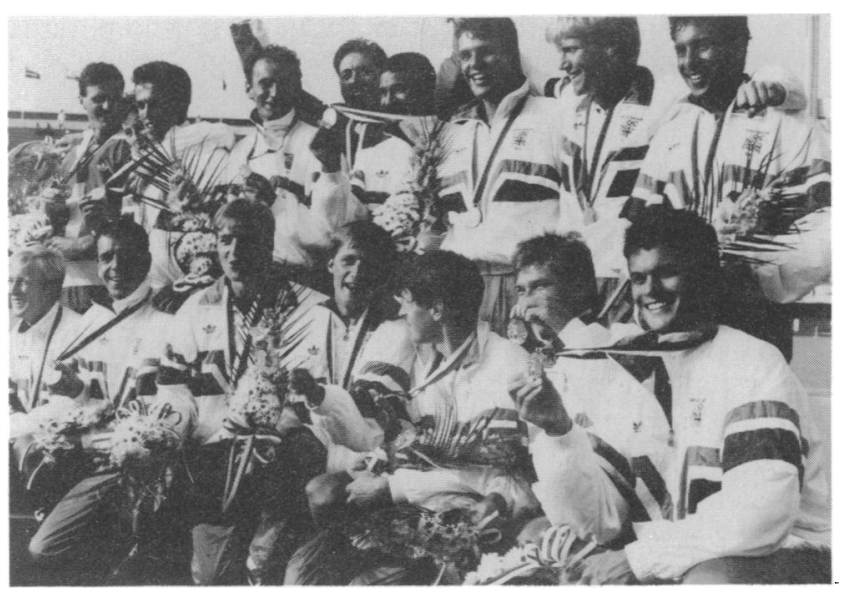

Figure 1. The 1988 Olympic Men's Hockey Gold Medallists: the Great Britain hockey squad

the medical team, who can also explain the situation to the selectors and management. One key member of the Great Britain hockey team had a number of niggling injuries in the build up to Seoul, both before the final squad was announced and continuing right up to a few weeks prior to departure. He was advised correctly on the management of his injuries. The team management was fully aware of the situation and stood by him, much to their credit. He came through his injuries well, and played in every match. I know there were times when all wondered if it was not time to select someone else.

I note that international oarsmen injured for more than 30 days a year are unlikely to get picked ${ }^{1}$. Rowing is of course a very different sport but in hockey this could result in a tremendous waste of talent. There are usually methods of maintaining a level of physical fitness that do not aggravate the injured part, for example swimming or an exercise cycle. Being injured at such a time is very frustrating but the player will overcome this more easily if he knows his interests are being looked after in the best way possible.

In the preparation for competition the doctor must obviously be responsible for advice regarding vaccination for foreign travel, and in the avoidance of the use of banned substances. A positive test on one player results in disqualification of the whole team, and it is in the team's interest that each player is advised correctly about these.

If I were a player with no medical knowledge I would expect to be given a list of common medications I could safely take and a list of those I could not, with strict instructions to seek advice before taking any medication not on the lists. If this is not done I would lay the blame for an accidental positive test at the door 
of the doctor. I would, of course, expect my doctor's advice to be correct.

Fortunately, drug abuse is not a problem in international hockey. I know steps are being taken in this country to ensure that this remains the case, but as in all sports it is less easy to control the problem worldwide. I am totally against drug abuse, particularly anabolic steroids and note two recent case reports of myocardial infarction occurring in young people using them ${ }^{2}$. I do have some sympathy, however, with those athletes who have to choose either to break the rules in order to compete with those who get away with it or to accept defeat. Until it is fairly and equally controlled worldwide, the problem will continue to exist.

Once in competition, players need advice on diet, appropriate hydration (especially in hot and humid climates) and on adequate rest. Some players need as much massage to their brains as to their tired limbs! Often players need to be able to let off steam or have a moan about something that would not be appropriate with either other players or management. The medical team represent a middle ground and have their role as listeners as well as advisers.

The team doctor's obligation is to his patient. On the other hand he is the team doctor and will be required to advise management as to the fitness or otherwise of a player. This can present obvious problems. In theory, the doctor must still be bound by confidentiality, and discussing a player's condition with the manager is analogous to discussing a patient with his employer. It is an ethical problem that many could probably discuss at length but, fortunately, remains theoretical in hockey circles. All the hockey players are aware that the team comes first - if they did not, they would not have got this far. Perhaps this is a reflection of the so called amateur spirit that our victory in Seoul was said to exemplify.

In short, the team doctor needs an 'holistic' approach - the whole athlete, the whole team plus the management and for the whole time, from the start of training to the finish of the tournament, not to mention treating the hangovers the morning after a gold medal celebration!

\section{References}

1 Budgett, R.G. McB. The road to success in international rowing. Br J Sports Med 1989, 23, 49-50

2 Bowman, S.J., Tanna, S., et al. Anabolic steroids and infarction. Br Med J 1989, 299, 632 